\title{
XXXI. On the causes of the semi-diurnal fluctuations of the barometer
}

\section{Thomas Hopkins Esq.}

To cite this article: Thomas Hopkins Esq. (1846) XXXI. On the causes of the semi-diurnal fluctuations of the barometer, Philosophical Magazine Series 3, 28:186, 166-175, DOI: $10.1080 / 14786444608645392$

To link to this article: http://dx.doi.org/10.1080/14786444608645392

曲 Published online: 30 Apr 2009.

Submit your article to this journal

Џ Article views: 2

Q View related articles $₫$ 
$4^{\circ} \mathrm{C}$; ; with steel when it amounted to $2^{\circ}$ or $3^{\circ}$; and lastly, with lead, when $1^{\circ}$ of difference existed, it was not accurate.

2. The reason for this want of accordance between the observation and the mathematical law is, that in establishing the latter the outward and inward power of conduction of bodies was considered as independent of the temperature. If these be considered as functions of the temperature, a proximate formula for the distribution of heat in the rod may be established, which would very nearly agree with my observations.

3. The conducting powers of bodies established by former philosophers with the aid of Biot's law are consequently incorrect, and can only be considered as partial approximations to the truth.

4. The constant coefficient for the conducting power with a difference of temperature equal 0 , is therefore only to be determined in this manner; either by using Biot's law and observing the distribution of heat in the rod with very small differences of temperature, or more correctly, by ascertaining its value, as was done in the author's experiments by means of Poisson's formula.

5. That the method employed in the observations is accurate, and that the thermo-electrical battery will become in the hands of natural philosophers a more correct means of ascertaining the temperature of the surfaces of bodies than any other, and may be used in cases where the common thermometers cannot be employed.

XXXI. On the Causes of the Semi-diurnal Fluctuations of the Barometer. By Thomas Hopkins, Esq.*

THAT the non-condensable gases and the aqueous vapour 1 of the atmosphere, when it is at rest, press on the mercury of the barometer independently of each other, and constilute the general atmospheric pressure, is evident from their known laws of diffusion and independent existence while diffused through each other.

But that the facts and reasonings, commonly adduced, resting on those circumstances, together with the daily alterations of thermometic temperature, account for the two risings and the two fallings of the barometer, as is contended by some parties, cannot be admitted.

In certain parts, such as Canada, of which an account has been recently given by Colonel Sabine, the influence of the causes named may be sufficient to account for a considerable

* Read to the Literary and Philosophical Society of Manchester, Dec. 30,1845 , and communicated by the Author. 
portion of the semi-diurnal movements of the barometer which occur in that country; but these causes are not sufficient to produce the diurnal fluctuations in other places, such as Bom.bay, Calcutta and La Guayra. And there can be little doubt that the real causes, whatever they may be, which give rise to the double undulations in these tropical parts, produce them in places where they are less extensive, although the operation of the causes in the latter places may be weaker and more difficult to trace,

I have shown in my "Atmospheric Changes" that there is no reason to believe that the daily warming of the atmospheric gases by the direct influence of the sun produces any appreciable alteration in their pressure on the morcury of the barometer, as the effect of that warming on the whole column in the locality is so small, as to prevent much disturbance of atmospheric pressure; yet great influence has been attributed to solar heating near the surface in producing the semi-diurnal fluctuations that take place.

Colonel Sabine, in his Report on the Meteorology of Toronto at the meeting of the British Association in 1844, gives an explanation of the daily oscillations. He says, "As the temperature of the day increases, the earth becomes warmed and imparts heat to the air in contact with it, and causes it to ascend. The column of air over the place of observation thus warmed rises, and a portion of it diffuses itself in the higher regions of the atmosphere, where the temperature at the surface is less. Hence the statical pressure of the column is diminished. On the other hand, as the temperature falls, the column contracts, and receives in its turn a portion of air which passes over in the higher regions from spaces where a higher temperature prevails; and thus the statical pressure is augmented."

In the Athenæum of July 5,1845 , the Colonel is represented as having said at the then recent meeting of the British Association, that in Dr. Buist's Meteorological Report from Bombay, "the explanations thereby afforded of the diurnal variations of the gaseous pressure at Bombay, which, although at first sight more complex than at the stations of Toronto, Prague or Greenwich, he conceives to be equally traceable to variations of temperatures." Colonel Sabine therefore, after having examined Dr. Buist's neteorological registers, retains the opinion that the semi-diurnal alterations of the gaseous pressure are produced by alterations of temperature, as that temperature is shown by the thermometer.

As I propose to examine this theory and to compare it with another, it will be convenient to designate the two by distinct 
names. I shall therefore call the Colonel's "the temperature theory," and the other, "the condensation theory." Both of these rest on alterations of temperature; but the former depends on the temperature found by thermometric measurement near the earth's surface, and the latter on the temperature which must be produced by condensation of vapour in a higher part of the atmosphere, of which we have no direct measure.

The semi-diurnal fluctuations of the barometer are the greatest within the tropics; and as details of those at Bombay have not yet been published, we will proceed to examine accounts furnished by Kaemtz in his valuable work on Meteorology. In page 248 of that work we have the following tables of the hourly heights of the barometer :-

\section{TABLE I.}

Mean height of the barometer expressed in millimetres for all hours, and in different places.

\begin{tabular}{|c|c|c|c|c|c|c|c|c|}
\hline Places .... & Gt. Ocean. & Cumana. & La Guayra. & Calcutta. & Padua. & Halle. & Abo. & $\begin{array}{l}\text { Peters- } \\
\text { burg. }\end{array}$ \\
\hline Latitude... & $0^{\circ} 0^{\prime}$ & $10^{\circ} 23^{\prime} \mathrm{N}$. & $10^{\circ} 36^{\prime} \mathrm{N}$. & $22^{\circ} 35^{\prime} \mathrm{N}$. & $45^{\circ} 24^{\prime} \mathrm{N}$ & $54^{\circ} 29^{\prime} \mathrm{N}$. & $60^{\circ} 5 \bar{z}^{\prime} \mathrm{N}$. & $59^{\circ} 66^{\prime} \mathrm{N}$. \\
\hline Observers . & Horner. & Fumboldt. & $\begin{array}{l}\text { Boussin- } \\
\text { gault. }\end{array}$ & Balfour. & Ciminello. & Kaemtz. & $\begin{array}{c}\text { Hall- } \\
\text { stroem. }\end{array}$ & Kupffer. \\
\hline Noon & $752 \cdot 35$ & $756 \cdot 57$ & $759 \cdot 41$ & $759 \cdot 61$ & $757 \cdot 02$ & $753 \cdot 29$ & $759 \cdot 31$ & $759 \cdot 47$ \\
\hline 1 & 751.8 & 755.99 & $758 \cdot 91$ & $759 \cdot 22$ & & $753 \cdot 11$ & 759.29 & \\
\hline 2 & $751 \cdot 55$ & $755 \cdot 47$ & $758 \cdot 41$ & $758 \cdot 39$ & $756 \cdot 67$ & $752 \cdot 99$ & $759 \cdot 27$ & $759 \cdot 38$ \\
\hline 3 & $751 \cdot 15$ & & $758 \cdot 12$ & 758 & 756 & $752 \cdot 89$ & $759 \cdot 25$ & \\
\hline 4 & $751 \cdot 02$ & $754 \cdot 96$ & $758 \cdot 05$ & 757.91 & $756 \cdot 47$ & $752 \cdot 84$ & $759 \cdot 25$ & $759 \cdot 32$ \\
\hline 5 & & & $758 \cdot 10$ & $757 \cdot 93$ & $756 \cdot 46$ & $752 \cdot 86$ & $759 \cdot 27$ & \\
\hline 6 & $751 \cdot 71$ & $755 \cdot 41$ & $758 \cdot 40$ & 758 & 756.50 & $752 \cdot 91$ & $759 \cdot 29$ & $759 \cdot 31$ \\
\hline 7 & 751.93 & $755 \cdot 81$ & 758.90 & $758 \cdot 02$ & $756 \cdot 63$ & $753 \cdot 02$ & $759 \cdot 34$ & \\
\hline & $752 \cdot 35$ & & $759 \cdot 1$ & 758 & & $753 \cdot 14$ & $759 \cdot 39$ & $759 \cdot 32$ \\
\hline 9 & $752 \cdot 74$ & 756.59 & $759 \cdot 69$ & $759 \cdot 24$ & $756 \cdot 92$ & $753 \cdot 24$ & $759 \cdot 44$ & \\
\hline 10 & $752 \cdot 85$ & $756^{\circ}$ & 759 & 759 & & $753 \cdot 31$ & $759 \cdot 47$ & $759 \cdot 36$ \\
\hline 11 & $752 \cdot 86$ & $757 \cdot 15$ & $759 \cdot 98$ & $759 \cdot 09$ & $757 \cdot 02$ & $753 \cdot 29$ & $759 \cdot 47$ & \\
\hline Midnight & $752 \cdot 47$ & $756 \cdot 86$ & $759 \cdot 64$ & 758 & 757.01 & $753 \cdot 23$ & $759 \cdot 41$ & $759 \cdot 35$ \\
\hline 13 & $752 \cdot 20$ & 756.53 & $759 \cdot 34$ & $758 \cdot 62$ & 756.90 & $753 \cdot 14$ & $759 \cdot 33$ & \\
\hline 4 & $751 \cdot 77$ & $756 \cdot 21$ & $759 \cdot 05$ & $758 \cdot 57$ & $756 \cdot 84$ & $753 \cdot 05$ & $759 \cdot 24$ & $759 \cdot 32$ \\
\hline 15 & $751 \cdot 63$ & $755 \cdot 89$ & $758 \cdot 81$ & $758 \cdot 49$ & $756 \cdot 78$ & 752.99 & $759 \cdot 14$ & \\
\hline 16 & $751 \cdot 32$ & $755 \cdot 66$ & 758.68 & $758 \cdot 47$ & 756.74 & $752 \cdot 99$ & $759 \cdot 07$ & $759 \cdot 32$ \\
\hline 18 & $\begin{array}{l}751.65 \\
71.05\end{array}$ & & $758 \cdot 85$ & $758 \cdot 44$ & $756 \cdot 75$ & $753 \cdot 34$ & $759 \cdot 03$ & \\
\hline 19 & $752 \cdot 84$ & $\begin{array}{l}756 \cdot 18 \\
758 \cdot 58\end{array}$ & $\begin{array}{l}759 \cdot 32 \\
759.94\end{array}$ & $\begin{array}{l}758 \cdot 68 \\
759 \cdot 16\end{array}$ & $\begin{array}{l}756799 \\
756 \cdot 80\end{array}$ & $\begin{array}{l}753 \cdot 12 \\
73 \cdot 94\end{array}$ & $759 \cdot 04$ & $759 \cdot 39$ \\
\hline 20 & & 756.9 & 760 & 759 & 757.01 & $753 \cdot 37$ & $759 \cdot 15$ & $759 \cdot 49$ \\
\hline 21 & $753 \cdot 16$ & $757 \cdot 31$ & 759 & 760 & 757 & $753 \cdot 44$ & $759 \cdot 21$ & \\
\hline 22 & & 757 & $760 \cdot 50$ & $759 \cdot$ & $757 \cdot 14$ & $753 \cdot 46$ & $759 \cdot 29$ & 759.51 \\
\hline 23 & & $757 \cdot 01$ & $759 \cdot 99$ & $759 \cdot 09$ & $757 \cdot 07$ & $753 \cdot 40$ & $759 \cdot 32$ & \\
\hline
\end{tabular}

From an examination of this table, it will be seen that the fiuctuations are the greatest within the tropics, and they diminish, though not invariably, with the increase of latitude. 
The first column exhibits the fluctuations at the equator in the great ocean. The range extends beyond two millimetres, and the descent from 9 in the morning till 4 in the afternoon gives the whole extent of the range.

The two next columns show the alterations at Cumana and La Guayra, both above $10^{\circ}$ north latitude, and the ranges are nearly equal to that at the equator.

The fourth column shows the changes at Calcutta to be nearly as great as in the preceding places, but both this and the La Guayra columns exhibit singular irregularities in the earlier parts of the mid-day descents.

In the Padua column, $45^{\circ}$ north, the fluctuation is much reduced in the extent of its range, but retains the same general character.

In Halle, in latitude $54^{\circ}$, the alterations do not differ materially from those at Padua.

The changes are very small in Abo and Petersburg, and in the former place the second rise attains a greater height than the first.

To these it is desirable that we should add the following table (p. 170) of the height of the dry-and wet-bulb thermometers, and the difference between the two,-with the dewpoint and the height of the barometer at Plymouth for three years, as furnished by Mr. S. Harris, and published in the Ninth Report of the British Association (p. 167).

In all these places the temperature shows only a single fluctuation, such as is seen in the table of the thermometer at Plymouth, namely one rise generally from about 5 A.M. to 1 or 2 P.M., and one fall from that time until 5 the following morning. Now, if the temperature of the atmosphere, as marked by the thermometer, caused the diurnal fuctuations in the way supposed, we ought to have in all these places one undulation in the twenty-four hours instead of two,-the rise of temperature causing a decline of the barometer during the hotter part of the day, and the fall of temperature producing a rise of the barometer in the colder part. Yet Colonel Sabine himself says that at Bombay, where there is only one rise and one fall of temperature, there are two risings and two fallings of the barometer! And these movements of the barometer take place not only when that instrument is taken as the measure of the whole pressure of the atmosphere, but also when the vapour pressure is deducted, and the mercury of the barometer is taken as the measure of the gaseous pressure alone. These facts are opposed to, and are irreconcileable with, the temperature theory. 
TABLE II.

Table of the heights of the dry- and wet-bulb thermometers, and the difference between the two, together with the dewpoint and height of the barometer at Plymouth for three years.

\begin{tabular}{|c|c|c|c|c|c|}
\hline Hour. & $\begin{array}{l}\text { Thermo- } \\
\text { meter. }\end{array}$ & $\begin{array}{l}\text { Wet-hulb } \\
\text { therma- } \\
\text { meter. }\end{array}$ & Difference. & $\begin{array}{l}\text { Dew- } \\
\text { point. }\end{array}$ & Barometer \\
\hline $\begin{array}{c}1 \text { A.M. } \\
2 \\
3 \\
4 \\
5 \\
6 \\
7 \\
8 \\
9 \\
10 \\
11 \\
12 \\
1 \\
2 \\
3 \\
4 \\
4 \\
5 \\
6 \\
7 \\
8 \\
9 \\
10 \\
11 \\
12\end{array}$ & 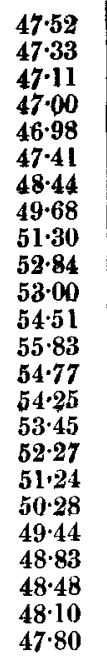 & $\begin{array}{l}46 \cdot 20 \\
46 \cdot 03 \\
45 \cdot 92 \\
45 \cdot 66 \\
45 \cdot 77 \\
46 \cdot 01 \\
46 \cdot 83 \\
47 \cdot 51 \\
48 \cdot 50 \\
49 \cdot 45 \\
50 \cdot 02 \\
50 \cdot 40 \\
50 \cdot 55 \\
50 \cdot 44 \\
50 \cdot 24 \\
49 \cdot 80 \\
49 \cdot 06 \\
48 \cdot 46 \\
47 \cdot 90 \\
47 \cdot 51 \\
47 \cdot 17 \\
46 \cdot 93 \\
46 \cdot 66 \\
46 \cdot 43\end{array}$ & $\begin{array}{l}1 \cdot 32 \\
1 \cdot 30 \\
1 \cdot 19 \\
1 \cdot 34 \\
1 \cdot 21 \\
1 \cdot 40 \\
1 \cdot 61 \\
2 \cdot 17 \\
2 \cdot 80 \\
3 \cdot 39 \\
3 \cdot 88 \\
4 \cdot 14 \\
4 \cdot 28 \\
4 \cdot 33 \\
4 \cdot 01 \\
3 \cdot 65 \\
3 \cdot 21 \\
2 \cdot 78 \\
2 \cdot 38 \\
1 \cdot 93 \\
1 \cdot 66 \\
1 \cdot 55 \\
1 \cdot 44 \\
1 \cdot 37\end{array}$ & $\begin{array}{l}45 \cdot 00 \\
44 \cdot 75 \\
44 \cdot 75 \\
44 \cdot 25 \\
44 \cdot 75 \\
44 \cdot 50 \\
45 \cdot 25 \\
45 \cdot 00 \\
45 \cdot 26 \\
46 \cdot 25 \\
46 \cdot 75 \\
46 \cdot 75 \\
46 \cdot 75 \\
46 \cdot 75 \\
46 \cdot 75 \\
46 \cdot 75 \\
46 \cdot 25 \\
46 \cdot 00 \\
45 \cdot 75 \\
45 \cdot 75 \\
45 \cdot 60 \\
45 \cdot 60 \\
45 \cdot 00 \\
45 \cdot 00\end{array}$ & $\begin{array}{l}29 \cdot 8017 \\
29 \cdot 7993 \\
29 \cdot 7944 \\
29 \cdot 7928 \\
29 \cdot 7928 \\
29 \cdot 7960 \\
29 \cdot 8002 \\
29 \cdot 8032 \\
29 \cdot 8048 \\
29 \cdot 8061 \\
29 \cdot 8045 \\
29 \cdot 8002 \\
29 \cdot 7957 \\
29 \cdot 7922 \\
29 \cdot 7908 \\
29 \cdot 7895 \\
29 \cdot 7938 \\
29 \cdot 7970 \\
29 \cdot 8019 \\
29 \cdot 8061 \\
29 \cdot 8094 \\
29 \cdot 8099 \\
29 \cdot 8092 \\
29 \cdot 8065\end{array}$ \\
\hline Mean ... & $50 \cdot 32$ & $47 \cdot 89$ & $2 \cdot 43$ & $45 \cdot 60$ & $29 \cdot 7999$ \\
\hline
\end{tabular}

As however the aqueous vapour of the atmosphere presses on the mercury of the barometer separately and independently, it has been attempted to be shown that the variable pressure of the vapour arising from difference in the quantity in the atmosphere at different periods of the day, combined with change of the gaseous pressure resulting from alteration of surface temperature, and that the two causes acting together produced the double undulation of the barometer; to this view therefore we will direct our attention.

The temperature wear the surface of the earth at Plymouth, as well as at the other places, rises from ahout 5 in the morning till about 2 in the afternoon; and when the wet bulb, as well as the dry thermometer, is used, as it was at Plymouth, it is seen that the temperature of the latter rises more than that of the former, or of the dew-point, and evaporation must consequently become progressively more active; 
there must therefore be successively more water evaporated and thrown into the atmosphere to be added to its woight. And according to the temperature theory, this water, now converted into vapour, must, up to say 10 o'clock, press with sufficient force on the mercury to counteract the lightening influence of the rising temperature, as during that time the barometer rises.

From 10 until 1 o'clock, as the temperature rises still higher, as compared with the wet-bulb thermometer and the dew-point, evaporation must go on increasing, and the increase of vapour pressure ought to continue; but it appears from the table not to do so, as the mercury of the barometer falls instead of continuing to rise; we have therefore to try to ascertain what can be the cause of this fall, while additional vapour is passing into the atmosphere.

Those who advance the temperature theory, say that the fall of the barometer is caused by the increasing temperature of the atmosphere produced by the action of the sun on the surfuce of the earth, and the air near to it; and they must maintain that this increase is sufficient, not only to lighten the atmosphere enough to cause the fall of the barometer, but also in addition to counteract the influence of the increased vapour pressure. Now at Plymouth the temperature rises from 5 to $10 \mathrm{~A}, \mathrm{M}$. nearly $6^{\circ}$, and may be supposed to lighten the atmosphere to a certain extent; at the same time evaporation throws vapour into the atmosphere. We are, however, required to suppose that the vapour produces so much greater effect by pressing on the mercury, than the heating of the atmosphere does in reducing atmospheric pressure, that the whole pressure becomes greater and the mercury rises. But after 10 o'clock the temperature continues to rise, but in a smaller degree, say nearly $3^{\circ}$, and vapour must be more abundantly thrown into the air, as is shown by the extent to which the wet-bulb the:mometer is kept down; yet the barometer, instead of continuing to rise, suddenly turns and falls, and continues falling

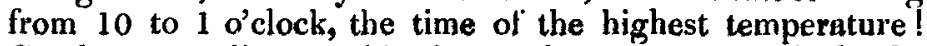
So that according to this theory, from 5 to 10 o'clock, the sun heats the air nearly $6^{\circ}$ and produces some vapour; and the two influences acting together cause the barometer to rise, but from 10 to 1 the sun heats the air about $3^{\circ}$, and must throw much additional vapour into the atmosphere; and then these two influences still acting together cause the barometer to fall! This is attributing opposite effects to the same causes, and must be presumed to be erroneous.

But let us examine the valuable Plymouth tables a little more minutely. The first column gives the temperature as 
shown by the ordinary thermometer; the second, the temperature of the wet-bulb thermometer, as kept down by the cooling influence of evaporation; and the third gives the difference between the two first. Now as this difference arises from the extent of the evaporation, the numbers of the difference may be taken to express the force and amount of evaporation, and to indicate the additional vapour that is discharged into the atmosphere. This force or amount at 5 o'clock in the morning is $1^{\circ} \cdot 21$, from which time it increases to $3^{\circ} \cdot 39$ at 10 o'clock. So that during this time, five hours, the increase in the force of evaporation is $2^{\circ} .18$; and this in the temperature theory must be held to be sufficient to overcome the lightening effect of a rise of $5^{\circ} .86$ of temperature, and also to raise the mercury of the barometer to the full extent of the morning rise! After this time, from 10 to 1 o'clock, the temperature rises further from $52^{\circ} \cdot 84$ to $55^{\circ} \cdot 83$ or $2^{\circ} \cdot 99$; and during the same period the force of evaporation increases $1^{\circ} \cdot 89$, that is, from $3^{\circ} \cdot 39$ to $4^{\circ} \cdot 28$. Thus we are required to believe, that from 5 to 10 in the morning, $2^{\circ} \cdot 18$ of evaporation overcame the lightening influence of $5^{\circ} \cdot 86$ of temperature, and in addition raised the mercury of the barometer; and from 10 to 1 in the day, $1^{\circ} 89$ of evaporation not only failed to overcome the lightening effect of $2^{\circ} .99$ of temperature, but allowed this relatively small amount of temperature to produce the further result of a fall of the mercury of the barometer. Or put in a tabular form, say that from

5 to 10 o'clock, $5^{\circ} \cdot 86$ of temperature and $2^{\circ} \cdot 18$ of evaporation caused a rise. 10 to $10^{\prime}$ clock, $2^{\circ} \cdot 99$ of temperature and $1^{\circ} \cdot 89$ of evaporation caused a fall !

That is, where temperature, the influence which lightens the atmosphere, is relatively great and should cause a fall, the mercury of the barometer rises; and where the influence of temperature is relatively small and should cause the vapour to produce a rise, the mercury falls! This must be erroneous.

In the same place, at Plymouth, from 1 o'clock until 4.M., as may be seen in the table, the temperature falls; and as far as that temperature acted the atmosphere would of course become heavier. At the same time evaporation shows vapour is passing into the atmosphere; it ought therefore to follow that the barometer should rise, and considerably too, through the operation at the same time of both the causes which are supposed to contribute to the production of a rise. But the barometer does not rise; on the contrary, it falls, and continues falling until 4 o'clock. 'These facts and reasonings prove that neither the daily variations of surface temperature, nor the different amounts of vapour pressure, nor both taken to- 
gether, are adequate to the production of the fall of the barometer from 10 to 4 o'clock in the day.

And if we proceed with our inquiries into the next period of six hours, that is, from 4 to 10 P.M., we meet wilh facts that do not harmonize with the temperature theory. During the whole of this time, it is true the temperature falls and the barometer rises: but the vapour pressure must have diminished according to the temperature theory, as the dew-point, the measure of vapour pressure, falls; and the lowering of the dew-point after 4 o'clock showed that vapour was then condensing in the lower part of the atmosphere. So that here it becomes necessary to suppose that the atmosphere cools enough, not only to raise the barometer to the full extent of its daily range, but also to counteract the reduction which takes place at the same time in the vapour pressure. Again, from 10 at night, although the atmosphere continued to cool, the barometer did not continue to rise, but once more fell, which fall is attributed to a diminution of vapour pressure. Thus from 4 to 10 in the afternoon and evening, cooling the atmosphere is represented as more powerful than reduction of vapour pressure; and from 10 in the evening to 4 in the morning, reduction of vapour pressure is supposed to be more powerful than cooling the atmosphere. The two forces, we are required to believe, do not merely neutralize each other, but each in its turn exercises a paramount influence, and for the time determines an absolute rise or a fall of the barometer; and this we are called upon to admit without any satisfactory or even plausible evidence being adduced to prove it.

What has been here advanced applies with the greatest force to the semi-diurnal fluctuations in atmospheric pressure which take place within the tropics. Aqueous vapour exists in the atmosphere in larger proportions in that part of the world than it does in higher latitudes; and it is to the daily condensation of that vapour in the atmosphere, and its subsequent evaporation there, that we are really to attribute the great deviation of the movements of atmospheric pressure from the daily march of temperature. If no vapour existed in the atmosphere, the alteration of pressure would be very little, and it would be the reverse of temperature. As the atmosphere became warmer, the pressure would be less; as it became colder, the pressure would be more. And the hourly variation in the quantities of vapour actually found in the atmosphere which arises from alteration of surface temperature, only introduces another element of pressure into the inquiry, which is simple in its character, - the vapour increasing or diminishing with an increase or diminution of temperature. 
If the two were equal while acting in opposite directions, they would balance each other. But the separate action of these two causes cannot produce such a double undulation of the mercury of the barometer as that which occurs daily in the tropical regions and at Plymouth.

The double undulation which takes place may be thus accounted for. When the sun acts with force on the surface of the earth in the morning, it heats that surface, and the air near it; increases evaporation of moisture from wet surfaces, and sends forth vapour', which presses on the mercury of the barometer and causes it to rise. The lower part of the atmosphere being heated also rises at the same time, probably in separate vertical streams, until it reaches a height where its expansion and consequent cooling is sufficient to condense a part of the vapour which it contains. A cloud is then formed, and the heat which has been evolved in the condensation of the vapour makes the cloud lighter than the adjoining air. The vapour in the upper part of the air being thus removed by conversion into water, no longer presses as vapour, or with the same force on that below; and the lower vapour consequently rises more freely to the height of the cloud: Both the air and vapour are also (speaking in popular language) drawn up by the ascending cloud, and fresh air flows in from adjoining low levels, forming what in some parts is called the sea breeze. Cloud more or less thick is now formed, more heat is liberated, and a larger mass of air heated, which being forced upwards expands and makes the whole atmospheric column lighter, and reduces the pressure on the surface below. Under ordinary circumstances this process proceeds while the sun acts with considerable power on the surface of the earth, which is generally from 10 A.M. to 4 . P.M., when day-cloud ceases to form. In this way, from 10 in the morning till 4 in the afternoon, the barometer is caused to fall, through the condensation of vapour in the upper part of the ntmosphere making the column of air warmer and lighter. But now as vapour no longer ascends, cloud ceases to form, but that cloud which had been formed remains suspended in the nir, where it begins to cool from the influence of evaporation of the particles of water that form the cloud. When it cools sufficiently, it becomes heavier and sinks, and additional air flows towards and over it, increasing the weight of the whole column in the loculity and causing the barometer to rise. By 10 the heavy air produced by cloud evaporation has partly descended and diffused itself on the surface of the earth, forming what is called the land breeze; and during the same time the cold of the surface condenses some of the va- 
pour into dew, when the atmosphere becomes somewhat lighter up to about 4 or 5 in the morning.

As we proceed from the equator towards higher latitudes, we find less vapour in the atmosphere, and its influence on atmospheric pressure is less marked. At Padua the fall of the barometer from 10 to 4 in the day is not much more than one-fourth the extent that it is at the equator, and at St. Petersburg it is very small. In situations where there is not sufficient vapour in the atmosphere to form any daily cloud, it is to be presumed that if a barometrical registration were to be made, there would be no double movement exlibited showing a fall from 10 A.M. to 4 P.M., and a rise from to 10 P.M., because there would be no condensation and warming to produce the former, nor evaporation and cooling to cause the latter.

The heating effects of condensing vapours may however be traced even in comparatively dry latitudes, such as that of 'Toronto, as shown in Col. Sabine's report to the British Association in 184.4. There was no fall of the barometer at that place from 4 to 10 in the morning, although the temperature had risen from $39^{\circ} .20$ to $46^{\circ} \cdot 35$, above $7^{\circ}$; but in the middle of the day, from 10 to 4 , with an increase of temperature from $46^{\circ} \cdot 35$ to $50^{\circ} \cdot 55$, being only $4^{\circ} \cdot 20$, the gaseous as well as the general atmospheric pressure was materially reduced! notwithstanding that the increase in the quantity of vapour during this time must have been as great as it was in the preceding period; and if this increased quantity had remained in the atmosphere, its pressure must have been added to that which previously existed. We are then obliged to suppose that the reduction of the pressure which took place immediately after 10 o'clock, arose from a cause which came into operation at that time; and that cause it is contended can be found only in the heating of the atmosphere by the condensation of vapour.

The great defect of the temperature theory is, that it fails to account for the fall of the barometer from 10 A.M. to 4 P.M., and its subsequent rise from 4 to 10 P.M., though this is the oscillation for which we have particularly to account; whilst the theory here maintained points out the cause of these, as well as the other diurnal, and also of the casual movements of the barometer. We are therefore at liberty to conclude that the semi-diurnal fluctuations of the barometer can be accounted for only on the condensation theory. 